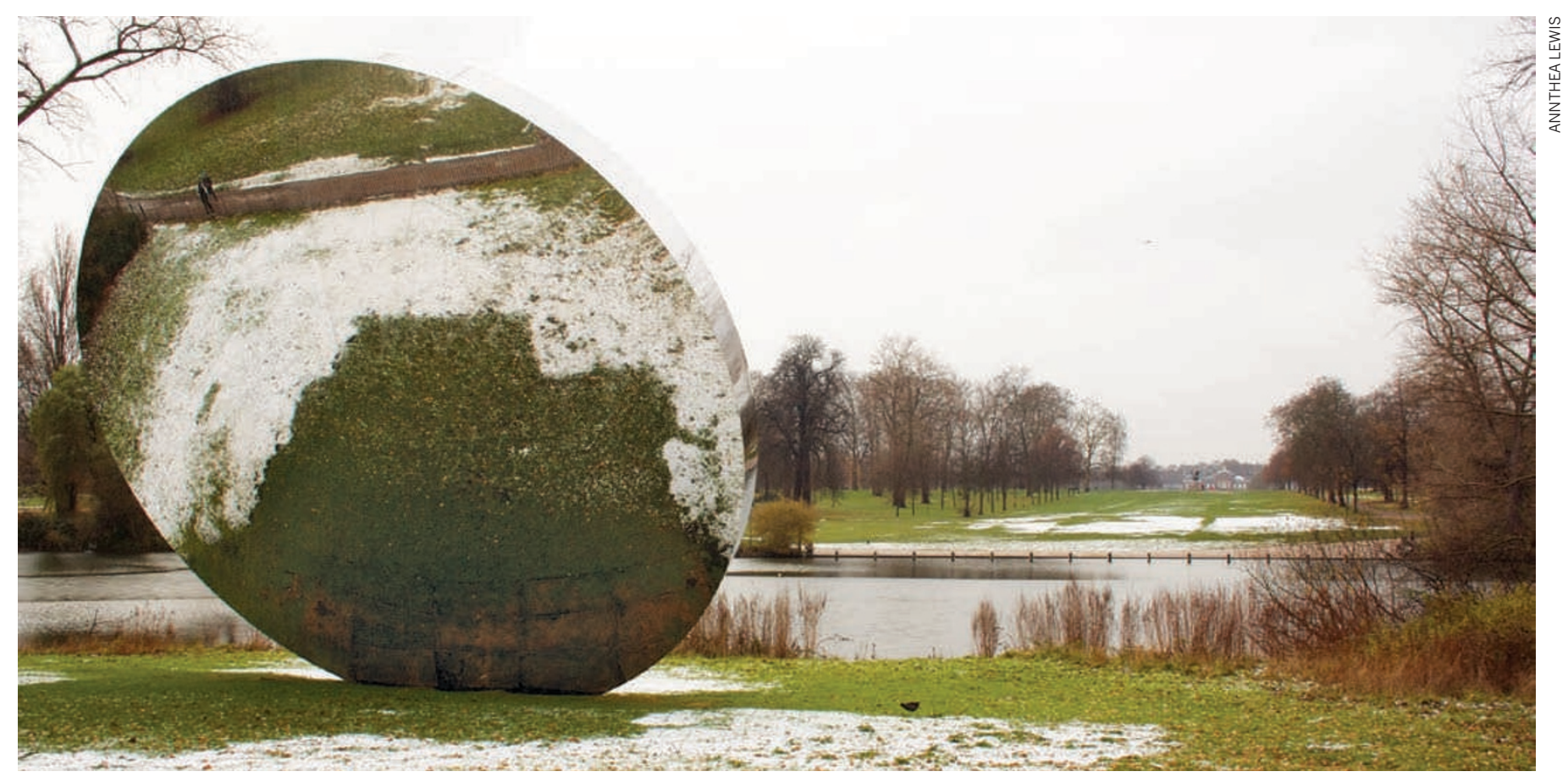

Sky Mirror (2006) in London's Kensington Gardens is one of four Anish Kapoor works manufactured by the process that is used to grind scientific optics.

\title{
SCULPTURE
}

\section{Engineering art}

\section{Neil Dodgson admires the technical mastery of sculptor Anish Kapoor.}

\section{I} ndian-born British artist Anish Kapoor is famous for his architectural sculptures and vivid use of colour. His works are also feats of engineering - his speciality at university before he left to pursue his art. From ArcelorMittal Orbit, a tower of twisted steel chosen as the centrepiece for London's 2012 Olympic park, to Svayambh, a gliding slab of blood-red wax, the significance of Kapoor's installations lies in how they are built.

Kapoor, who is exhibiting in London, New Delhi and Mumbai, regards his sculptures as embodiments of "mythologies" that include the process of their creation. "Meaning is gradually constructed, just as the object is constructed," he explains. The shows in India highlight his dynamic artworks - shown in the past year at London's Royal Academy and at the Guggenheim Bilbao in Spain — which use machinery to evoke a sense of change. His current London exhibition, in Kensington Gardens, features four highly polished stainless-steel forms that distort reflections of their surroundings like fairground mirrors.

The genesis of that series lies in Kapoor's collaboration with Cecil Balmond, head of the Advanced Geometry Unit at engineering firm Arup. Kapoor first worked with Balmond a decade ago to produce a sculpture for the cavernous turbine hall at London's Tate Modern. He helped Kapoor to refine his aesthetic ideas, bringing expertise in construction techniques, the tensile strengths of materials and the limits of manufacturing. The product was Marsyas (2002) two massive steel rings

Anish Kapoor: Turning the World Upside Down Kensington Gardens, London, until 13 March 2011.

Anish Kapoor National Gallery of Modern Art, New Delhi, until 27 February 2011; and at Mehboob Studios, Mumbai, until 16 January 2011. joined by a red PVC membrane stretched 140 metres between them, supporting a third steel toroid above visitors' heads. Balmond reprogrammed Arup's in-house software to model the membrane's precise form.

A discarded design later appeared in Chicago as Cloud Gate (2004): a 10-metrehigh, jelly-bean-like arch of polished steel. The forms in Kensington Gardens are similar in style. Cut from segments of a sphere, they were produced by the same process that is used for grinding large scientific optics. One, C-Curve (2007), reminds me of a smaller mirror in my office: a relic of a prototype threedimensional television. That too is beautifully made, but its bending of light is directed by a practical purpose. By contrast, Kapoor's curved mirrors are engineered to reflect the viewer's inner world.

In Kapoor's recent foray into dynamic works, now on show in India, exquisite engineering underlies other mythologies. In Svayambh (2007), an enormous block of red wax creeps along a hydraulic track, apparently being shaped as it passes through several gallery doorways. The name derives from a Sanskrit word, referring to that which is created of its own accord, rather than by a human hand. In fact, little wax is scraped off the installation after its first pass. Kapoor delights in this fiction: "The wax is not literally carved by the doorways, although it appears to be."

Kapoor's meanings are complex and layered. Svayambh, he explains, represents geology, body, blood and viscera, among other themes. It is difficult to engineer such a piece, with its combination of motors, mechanism and soft material requiring careful design and constant maintenance. Questioning the artist's intentions and methods unveils the fiction that the artwork formed itself.

A second wax piece seems more convincingly self-made. Shooting into the Corner (2008-09) is a large air-fired gun that fires 11-kilogram cylinders of red wax across the gallery every 20 minutes. The result is 
a chaotic pile. No artist directs its creation; random perturbations are caused by variations in the consistency of the wax, the gun pressure and in how the deposits accumulate. Yet it is stage-managed. The art is not in the wax mound but in the whole performance.

Another artful machine generated a set of extruded grey concrete sculptures called Greyman Cries, Shaman Dies, Billowing Smoke, Beauty Evoked (2008-09). These were produced by a scaled-up version of a rapid prototyping machine. Such technology is normally used by engineers to build accurate models from fine threads of molten plastic. Kapoor's larger version extrudes a thick concrete sausage that builds up layers of soft coils, ropes and worms under computer control.

Whereas engineers seek precision with their models, Kapoor delights in his products' imperfections. Yet the appearance of randomness involves technical sleights of hand. To achieve each particular texture, his contraption must be finely tuned. Kapoor deliberately finds a point of balance between opposites - between perfection and imperfection, softness and firmness, movement and repose - to tantalize the viewer.

Kapoor knows he is treading a fine line between artist and entertainer. He says: "It's a short trip from Disneyland to something truly mysterious." But that mystery is delivered only through precise engineering.

Neil Dodgson is professor of graphics and imaging at the University of Cambridge, UK. e-mail:neil.dodgson@cl.cam.ac.uk

\section{Measure for measure}

\section{A useful guide to citation analysis shows that counting publications is harder than it looks, finds Ton van Raan.}

$\mathrm{C}$ itation analysis offers a means to quantify the impact of a scientist's work. One tool for tracking citations is the Publish or Perish (PoP) software program developed by Anne-Wil Harzing, professor of international marketing at the University of Melbourne, Australia. Her guide describes how her program generates citation analyses from Google Scholar and gives an overview of bibliometric methods and sources. She champions the practical use of citation measures, yet also recognizes that calculating them reliably is a difficult task.

The Publish or Perish Book focuses on citation analysis of individual researchers, not groups or institutes. Several metrics may be calculated for scientists and for journals, including their number of publications and citations, average number of citations per publication and per author, and the h-index, a widely used characterization of citation impact. Harzing argues using practical examples that such indicators are good markers of a researchers' influence, and are useful in assessing applications for jobs, promotion and tenure, and for literature research and choosing a journal in which to publish.

Using Google Scholar as a data source is advantageous as it retrieves publications not covered by Thomson Reuters' Web of Science: books, edited volumes and 'grey' literature such as conference proceedings. Harzing explains how to analyse citations with Google Scholar, and discusses ways that citation patterns of early reports can be used to predict the later impact of journal articles derived from them. But there are inevitable problems in tying together varied data, such as matching conference proceedings with the subsequently published paper.

Harzing considers the main downside of the Web of Science to be its limited coverage of different disciplines, particularly of engineering, the social sciences and the humanities. In my view, however, its coverage of well-funded fields, such as the natural sciences and medicine, is very good. For novice users, the Web of Science does have trouble identifying ambiguous author names, especially those in which the order of the first name and surname is unclear. It

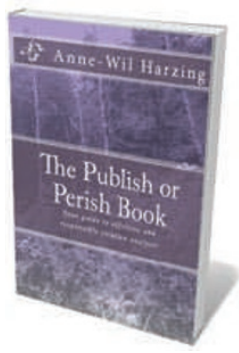

The Publish or Perish Book: A Guide to Effective and Responsible Citation Analysis ANNE-WIL HARZING Tarma Software Research: 2010 250 pp. $\$ 29.95$ also struggles to aggregate articles with variations of the same title and to identify self-citations. But professional bibliometricians such as myself build and work from Web of Science reconstructions - usually proprietary to their institutes - in which such sources of error are fixed.

The book underplays the ethical issues that arise when performing a citation analysis for a person other than yourself. Verification of research output is important - missing just one highly cited paper can distort the results dramatically. This highlights the necessity of cleaning raw data. For instance, incorrect referencing will lead to cited publications being missed. It is a huge effort to correct for these 'homeless' citations. In this respect, Google Scholar is a black box.

Harzing discusses both the perspective
D NATURE.COM

For our Science

Metrics special, see: go.nature.com/nj2xqk of the person to be evaluated, and that of the evaluator. This is important because evaluators of tenure promotions might apply home-made metrics that are not transparent and may incorporate unknown mistakes. Citation metrics are attractive because they have the potential of objectivity, but evaluators may put too much faith in quantitative aspects of research performance. Simple metrics then become a shortcut to decision-making.

Many scientists are concerned that citation analysis, particularly that done in an amateurish way, is having detrimental effects on science. They fear that researchers are driven to pursue citation quantity instead of scientific quality. Statistical reliability may become a serious problem when dealing with individuals rather than groups, as Harzing recognizes. Field-specific normalization is also necessary if research impact is to be compared across disciplines.

Further statistical factors limit metrics. Indicators often concern arithmetic mean values, yet the distribution of citations across publications is skewed. Averages are thus not the best statistic. Although this problem is discussed, Harzing's book doesn't offer indicators that are related to the distribution of impact across a field, which would answer the question 'Does he or she belong to the top $10 \%$ of his or her field?'

Harzing explains that the problem of the skewed distribution can be removed using the h-index: for instance, a researcher has an $\mathrm{h}$-index of ten if ten of his or her papers have at least ten citations and the other papers have no more than ten citations each. But in my view, the h-index is inconsistent. For example, suppose that researcher A has three publications with five citations each $(h=3)$ and researcher B has four with four citations each $(h=4)$. Both obtain one additional publication with five citations. Researcher A's h-index then increases to four, whereas researcher B's h-index remains equal to four. This makes no sense.

With these caveats in mind, The Publish or Perish Book is a useful resource for scientists, particularly in fields in which Google Scholar is a major source of citations.

Ton van Raan is professor of science studies in the Centre for Science and Technology at Leiden University, the Netherlands. 